\title{
SUPPORTED CYCLOPENTADIENYLMETAL CARBONYL COMPLEXES
}

\section{II *. POLYSTYRENE-SUPPORTED CARBONYL AND NITROSYL DERIVATIVES OF GROUP VI TRANSITION METALS}

\author{
GIUSEPPE GUBITOSA ** and HANS H. BRINTZINGER *** \\ Fachbereich Chemie Universität Konstanz, D.7750 Konstanz (B.R.D.)
}

\section{Summary}

Tricarbonyl hydride derivatives of cyclopentadienyl-chromium, -molybdenum and -tungsten compounds covalently linked to a macroreticular polystyrene support are obtained by treatment of polystyrene-attached cycloperitadienyl anions with the respective metal hexacarbonyl and subsequent acidification. In contrast to the ease with which unsupported cyclopentadienyl-chromium and -molybdenum tricarbonyl hydrides lose $\mathrm{H}_{2}$ to form dinuclear carbonyl species, no $\mathrm{H}_{2}$ is released from their polymer-supported counterparts below about $180^{\circ} \mathrm{C}$, and no dinuclear species are detectable after partial thermal decomposition at higher temperatures. The identity of the polymer-supported chromium species is confirmed by its conversion into nitrosyl derivatives.

\section{Introduction}

The reaction patterns of polymer-supported organometallic compounds and their potential applications in cataly tic processes are receiving much attention at present, and we recently initiated a study on polymer-supported cyclopentadienylmetal carbonyl compounds [1]. This class of compounds is particularly suitable for an investigation of fundamental structures and modes of reaction because of the easily detectable IR spectra, restricted structural parameters of these half-sandwich derivatives and the availibility of data on the homogeneous reference systems. We describe below the synthesis and characterization of cyclopentadienyl-chromium,-molybdenum and -tungsten derivatives covalently

\footnotetext{
- For part I see ref. 1.

* On leave fom Donegani Research Institute, Novara. Italy.

* * To whom corcempondence should be addressed.
} 
linked to a macroreticular, cross-linked polystyrene-18\% divinylbenzene copolymer.

Results and discussion

1. Synthesis and characterization of chromium, molybdenum and tungsten tricarbonyl hydride derivatives

Group VI transition metal tricarbonyl species are introduced to a polymer network by treatment of polystyrylmethylenecyclopentadienyl * anion, [2] (PS)- $\mathrm{CH}_{2}-\mathrm{C}_{5} \mathrm{H}_{4}^{-}$, containing about $1.5 \mathrm{mmol} \mathrm{C}_{5} \mathrm{H}_{4}^{-}$per $\mathrm{g}$ of polymer, with chromium, molybdenum or tungsten hexacarbonyl, in dimethyl formamide at $130^{\circ} \mathrm{C} \mathrm{[3],} \mathrm{subsequent} \mathrm{removal} \mathrm{of} \mathrm{excess} \mathrm{hexacarbonyl,} \mathrm{and} \mathrm{acidification} \mathrm{with}$ acetic acid.

The yellowish tungsten compound obtained after reaction for $4 \mathrm{~h}$ contained $0.94 \%$ tungsten; corresponding to $0.051 \mathrm{mmol} \mathrm{W}$ per $\mathrm{g}$ of polymer or about one cyclopentadienyltungsten unit per 200 styryl units. By extending the reaction time to $24 \mathrm{~h}$, a tungsten contents of up $5 \%$ can be obtained, corresponding to $0.25 \mathrm{mmol} W$ per $\mathrm{g}$ of polymer or about one cyclopentadienyltungsten unit per 40 styryl units.

Upon heating to temperatures of $200-220^{\circ} \mathrm{C}$, these materials release 2.95 $\pm 0.05 \mathrm{mmol} \mathrm{CO}$ and $0.45 \pm 0.05 \mathrm{mmol} \mathrm{H}_{2}$ per mmol $W$ present, and the IR spectra of the thermolysis products show no carbonyl bands. The results are consistent with the expected composition (PS) $-\mathrm{CH}_{2}-\mathrm{C}_{5} \mathrm{H}_{4} \mathrm{~W}(\mathrm{CO})_{3} \mathrm{H}$. This assignment is further supported by IR spectral data: two strong, terminal COabsorption bands ** of the polymer-supported material at 2020 and $1920 \mathrm{~cm}^{-1}$ are almost indistinguishable in position and relative intensity from those of $\mathrm{C}_{5} \mathrm{H}_{5} \mathrm{~W}(\mathrm{CO})_{3} \mathrm{H}$ [4]. Similar spectra, resembling those of $\mathrm{C}_{5} \mathrm{H}_{5} \mathrm{M}(\mathrm{CO})_{3} \mathrm{H}$ derivatives, are obtained for the corresponding chromium and molybdenum compounds (Table 1). The molybdenum derivative is formed by substitution of $\mathrm{Mo}(\mathrm{CO})_{6}$ faster than the derivatives of the other two metals and a molybdenum content of $4.5 \%$ (4.7 mmol Mo per $g$ of polymer or about one cyclopentadienylmolybdenum unit per 20 styryl units) is obtained after only $4 \mathrm{~h}$. An increased reactivity of $\mathrm{Mo}(\mathrm{CO})_{6}$ in comparison to $\mathrm{Cr}(\mathrm{CO})_{6}$ and $\mathrm{W}(\mathrm{CO})_{6}$ has been observed by Fischer et al. [3] in reiated substitution reactions with $\mathrm{C}_{5} \mathrm{H}_{5}^{-}$. The polymersupported metal compounds were further characterized by thermoanalytical studies. The materials undergo endothermic decompositions with loss of $\mathrm{H}_{2}$ and $\mathrm{CO}$ at temperatures of about $200-210^{\circ} \mathrm{C}$. Loss of $\mathrm{C}_{5} \mathrm{H}_{5}$ and $\mathrm{C}_{5} \mathrm{H}_{6}$ is observed at $170-230^{\circ} \mathrm{C}$.

The thermal stability of the polymer-supported cyclopentadienylmetal tricarbonyl hydrides, particularly those of chromium and molybdenum, up to temperatures close to the melting points of the polymer matrix contrasts sharply with the thermal instability of $\mathrm{C}_{5} \mathrm{H}_{5} \mathrm{Cr}(\mathrm{CO})_{3} \mathrm{H}$ and $\mathrm{C}_{5} \mathrm{H}_{5} \mathrm{Mo}(\mathrm{CO})_{3} \mathrm{H}$. These compounds are known to lose $\mathrm{H}_{2}$ at temperatures of about $50^{\circ} \mathrm{C}$ with formation of

\footnotetext{
* (PS) = polystyryl.

* IR absorptions due to $\mathrm{M}-\mathrm{H}$ vibrations cannot be distinguished from background absorptions in these polymeric materials; they are reported to be relatively weak in the analogous compounds $\mathrm{C}_{5} \mathrm{H}_{5} \mathrm{Mr}(\mathrm{CO})_{3} \mathrm{H}[6]$.
} 
TABLE 1

IR ABSORPTION DATA IN THE v(CO) ABSORPTION RANGE (in $\mathrm{cm}^{-1}$ )

\begin{tabular}{lll}
\hline & $(P S)-C_{2}-C_{5} H_{4} M(C O)_{3} \mathrm{H}$ & $\left.C_{5} \mathrm{H}_{5} \mathrm{MICO}\right)_{3} \mathrm{H}(\mathrm{ref} .4,5)$ \\
\hline Cr & 2020,1920 & $2018,1934,1908,1888$ \\
Mo & 2030,1930 & $2030,1949,1913 \mathrm{w}$ \\
$W$ & 2020,1925 & $2020,1929.1980 \mathrm{w}$ \\
\hline
\end{tabular}

the binuclear species $\left[\mathrm{C}_{5} \mathrm{H}_{5} \mathrm{M}(\mathrm{CO})_{3}\right]_{2}$ [3]. The dinuclear molybdenum and tungsten compounds are readily distinguished from their mononuclear tricarbonyl hydride precursors by their characteristic IR spectra [7-9]. No absorption bands assignable to such a dimer are observed, however, when IR spectra of the polymer-supported tricarbonyl hydride compounds are mcnitored during their thermolysis, Instead, the frequencies of their $\mathrm{CO}$ absorption bands remain unchanged while these bands disappear gradually and simultaneously. We conclude, therefore, that the mutual isolation of the cyclopentadienylmetal centers by their attachment to a rigid, cross-linked polymer matrix, at the relatively low degrees of substitution present, precludes metal-metal interactions except for a negligible statistical fraction of the metal centers present. The very great retardation of the thermal release of $\mathrm{H}_{2}$ from the polymer-supported tricarbonyl hydride derivatives compared with that from the unsupported analogues accordingly indicates that the rate-determining step of the normal $\mathrm{H}_{2}$ evolution in homogeneous solution involves a binuclear species which is not available for the polymer-supported compound. This would exclude, e.g., a monomolecular, homolytic cleavage of thermal Mo- $\mathrm{H}$ bond with formation of radical species as the rate-determining step of the $\mathrm{H}_{2}$ evolution in homogeneous solution.

For $\mathrm{C}_{5} \mathrm{H}_{5} \mathrm{~W}(\mathrm{CO})_{3} \mathrm{H}$, a photoinduced dimerisation has also been reported [3]. UV-irradiation of (PS) $-\mathrm{CH}_{2}-\mathrm{C}_{5} \mathrm{H}_{4} \mathrm{~W}(\mathrm{CO})_{3} \mathrm{H}$ does not cause spectral changes which could be ascribed to a polymer-bound analogue of $\left[\mathrm{C}_{5} \mathrm{H}_{5} \mathrm{~W}(\mathrm{CO})_{3}\right]_{2}$; an unidentified species with IR absorptions at 1920 and $1850 \mathrm{~cm}^{-1}$ appears as an intermediate after partial photolysis.

\section{Nitrosyl derivatives}

We have further characterized the polymer-supported compounds described above and extended their reaction patterns by converting them to other species with characteristic, easily identifiable IR spectra, especially nitrosyl derivatives.

Reaction of (PS) - $\mathrm{CH}_{2}-\mathrm{C}_{5} \mathrm{H}_{4} \mathrm{Cr}(\mathrm{CO})_{3} \mathrm{H}$ with $\mathrm{NO}$ in dioxane/water leads to a yellow product with IR absorptions at 2020 and $1945 \mathrm{~cm}^{-1}(\nu(C O))$ and an additional band at $1705 \mathrm{~cm}^{-1}(\nu(\mathrm{NO}))$. The close agreement of these spectral data with those reported for $\left(\mathrm{C}_{5} \mathrm{H}_{5}\right) \mathrm{Cr}(\mathrm{CO})_{2} \mathrm{NO}[10,11]$ indicate that the mixed carbonyl nitrosyl derivative (PS) $-\mathrm{CH}_{2}-\mathrm{C}_{5} \mathrm{H}_{4} \mathrm{Cr}(\mathrm{CO})_{2} \mathrm{NO}$ is formed.

When the tricarbonyl hydride is first converted into a chloride-containing species the reaction with NO takes a different course. When (PS) $-\mathrm{CH}_{2}-\mathrm{C}_{5} \mathrm{H}$ (CO) ${ }_{3} \mathrm{H}$ is heated in chloroform, one observes the intermediary formation of a derivative with weak IR absorptions at 2040,1990 and $1950 \mathrm{~cm}^{-1}$. Cumparison with IR data given for $\mathrm{C}_{5} \mathrm{H}_{5} \mathrm{Cr}(\mathrm{CO})_{3} \mathrm{X}$ derivatives ( $\mathrm{X}=$ halogen) [12], indicates that (PS) $-\mathrm{CH}_{2}-\mathrm{C}_{5} \mathrm{H}_{4} \mathrm{Cr}(\mathrm{CO})_{3} \mathrm{Cl}$ is formed. Continued treatment with $\mathrm{CHCl}_{3}$ 
SCHEME 1. Reaction scheme of polystyryImethy lenecy clopentadienylchromium derivatives. (Numbers in parentheses indicate characteristic iR absorption frequencies in $\mathrm{cm}^{-1}$.)

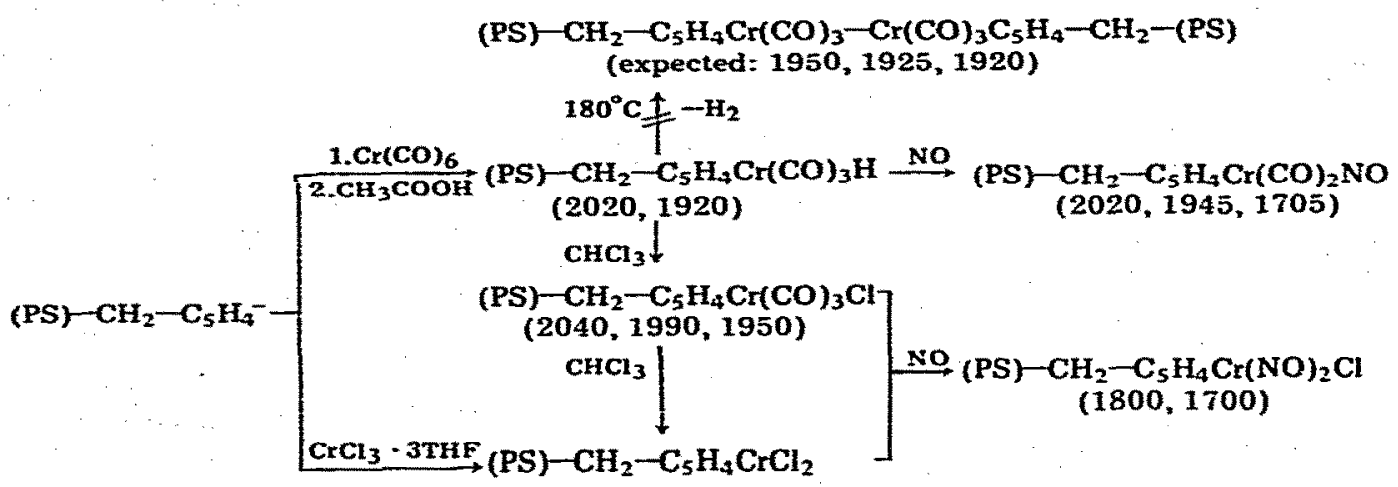

converts this material to another chloride derivative showing no $C O$ bands, presumably (PS) $-\mathrm{CH}_{2}-\mathrm{C}_{5} \mathrm{H}_{4} \mathrm{CrCl}_{2}$ (vide infra). Introduction of $\mathrm{NO}$ into the reaction mixture in $\mathrm{CHCl}_{3}$ leads, over a period of about $24 \mathrm{~h}$, to a green material, characterised as (PS) $-\mathrm{CH}_{2}-\mathrm{C}_{5} \mathrm{H}_{4} \mathrm{Cr}(\mathrm{NO})_{2} \mathrm{Cl}$ by two $\mathrm{NO}$ absorption bands at 1800 and $1700 \mathrm{~cm}^{-1}$, which are in close agreement with those reported for $\mathrm{C}_{5} \mathrm{H}_{5} \mathrm{Cr}(\mathrm{NO})_{2} \mathrm{Cl}[13]$. The identity of this material is further supported by its formation by an alternative synthetic route. In this, treatment of cyclopentadienyl anion with $\mathrm{CrCl}_{3}-3 \mathrm{THF}$ leads to (PS) $-\mathrm{CH}_{2}-\mathrm{C}_{5} \mathrm{H}_{4} \mathrm{CrCl}_{2}$ and reaction of this compound with $\mathrm{NO}$ gives the compound (PS) $-\mathrm{CH}_{2}-\mathrm{C}_{5} \mathrm{H}+\mathrm{Cr}(\mathrm{NO})_{2} \mathrm{Cl}$ as in the corresponding homogeneous reaction [13].

The data summarised in the Scheme 1 support the identity of the materials obtained and substantiate the view that the reaction modes of the polystyrenesupported cyclopentadienyimetal compounds largely parallel those of corresponding species in homogeneous solution as long as the reactions can proceed at isolated metal centers.

Material

\section{Procedures}

All reactions were carried out with exclusion of air, either in Schlenk equipment or on a vacuum manifold. Solvents were dried with $\mathrm{LiAlH}_{4}$ or $\mathrm{P}_{4} \mathrm{O}_{10}$ and distilled on a vacuum manifold immediately prior to use. Transfer of solid samples was performed in a nitrogen-filled glove box. Samples for IR spectra were prepared by crushing the polystyrene beads in an agate mortar under $\mathrm{N}_{2}$ and mulling a weighed amount of $10-15 \mathrm{mg}$ of the pulverised material with $0.5 \mathrm{ml}$ of air-free Nujol; spectra were then recorded in demountable $\mathrm{NaCl}$ cells with a $0.25 \mathrm{~mm}$ Teflon spacer.

For the analysis of chromium and of metal-bound chlorine, weighed samples of the polymer materials were treated with $15 \mathrm{ml}$ of $2 \mathrm{M} \mathrm{NaOH}$ or $\mathrm{KOH}$ for $24 \mathrm{~h}$ at $80^{\circ} \mathrm{C}$ and, in the case of $\mathrm{Cr}$ analysis, with $15 \mathrm{ml}$ of $30 \% \mathrm{H}_{2} \mathrm{O}_{2}$. After dilution, chromium was determined as $\mathrm{CrO}_{4}{ }^{2-}$ by spectrophotometric or iodometric meth- 
ods and chloride by potentiometric titration with $\mathrm{AgNO}_{3} . \mathrm{Molybdenum}$ and tungsten analysis were performed by Alfred Bernhard, Microanalytical Laboratories, 5251 Elbach BRD. For determination of the amount of evolved $\mathrm{CO}$ and $\mathrm{H}_{2}$, weighed samples of the polymeric materials were slowly heated to temperatures up to $220^{\circ} \mathrm{C}$ for periods up to $6 \mathrm{~h}$ in a Schlenk vessel connected to a vacuum manifold. Non-condensable gases were collected in a Toepler pump. After gas-volumetric determination of the sum of $\mathrm{CO}$ and $\mathrm{H}_{2}$, the mixture was converted into $\mathrm{CO}_{2}$ and $\mathrm{H}_{2} \mathrm{O}$ by passage through a $\mathrm{CuO}$ tube at $310^{\circ} \mathrm{C}$ and the amount of $\mathrm{CO}_{2}$ measured separately.

Thermoanalytic analyses were performed on a Netzsch 429 Thermoanalyzer, which permits simultaneous recording of weight and enthalpy changes and mass spectral analysis of gaseous products.

\section{Polystyrylmethylenecyclopentadiene}

Preparations were carried out as described in the literature $[2,14,15]$. As support material, beads $(0.5-0.7 \mathrm{~mm}$ diameter) of a macroreticular styrene$18 \%$-divinyl benzene copolymer with pore diameters of $250-350 \AA$ was used, which was obtained as a gift from Bayer AG. The $\mathrm{Cl}$ contents [15] after chloromethylation were $1.4-1.8 \mathrm{mmol} \mathrm{Cl} / \mathrm{g}$ polymer. Substitution with a three to four-fold excess of $\mathrm{C}_{5} \mathrm{H}_{5} \mathrm{Na}$ was carried out in refluxing tetrahydrofuran for two days; after this, the $\mathrm{Cl}$ content of the polymer was below $0.05 \mathrm{mmol} \mathrm{Cl} / \mathrm{g}$ polymer. After washing with methanol and tetrahydrofuran to remove all $\mathrm{NaCl}$, the materials were dried at $10^{-3}$ torr and room temperature for several days.

The $\mathrm{C}_{5} \mathrm{H}_{5}$ content of the products was determined by reaction with a two- to three-fold excess of $\mathrm{CH}_{3} \mathrm{Li}$ in tetrahydrofuran for three to four days and gasvolumetric determination of the amount of $\mathrm{CH}_{4}$ formed. The $\mathrm{C}_{5} \mathrm{H}_{5}$ contents thus determined are in close agreement with the difference between the $\mathrm{Cl}$ contents before and after reaction with $\mathrm{C}_{5} \mathrm{H}_{5} \mathrm{Na}$.

\section{Polystyrylmethylenecyclopentadienylmetal tricarbonyl hydrides}

A $5 \mathrm{~g}$ sample of the cyclopentadiene-substituted polymer $\left(1.42 \mathrm{mmol} \mathrm{C}_{5} \mathrm{H}_{5} / \mathrm{g}\right.$ polymer) was converted into the lithium salt as described in ref. $2 ; 1.6 \mathrm{~g} \mathrm{Cr}(\mathrm{CO})_{6}$ ( $7 \mathrm{mmol}$ ) and $60 \mathrm{ml}$ of dry dimethyl formamide were added and the mixture was heated to $130^{\circ} \mathrm{C}$ for $5 \mathrm{~h}$. After cooling to room temperature, the polymer was collected by filtration and washed with dry dimethyl formamide until the filtrate was free of carbonyl absorptions, and with ether to remove the dimethyl formamide. The material was then treated with $50 \mathrm{ml}$ of a $2 M$ solution of acetic acid in a 1/1 mixture of water and dioxane, filtered, washed neutral with water/ dioxane, with dioxane and finally with diethyl ether. The yellowish material was then dried at $10^{-3}$ torr and room temperature for two days.

The chromium content of this material was $1.55 \%$, IR absorptions at 2020 and $1920 \mathrm{~cm}^{-1}$ are in close agreement with those of $\mathrm{C}_{5} \mathrm{H}_{5} \mathrm{Cr}(\mathrm{CO})_{3} \mathrm{H}$ (Table 1). No absorptions assignable to arenemetal tricarbonyl species [16] are present in the IR spectra of these compounds.

Molybdenum and tungsten derivatives were prepared analogously.

Photolysis of polystyrylmethylenecyclopentadienyltungsten tricarbonyl hydride A $200 \mathrm{mg}$ sample of the crushed polymer-supported tricarbonyl hydride deri- 
vative was stirred with $8 \mathrm{ml} \mathrm{n}$-heptane in a quartz test tube with exclusion of air, and the mixture was irradiated at room temperature with light from a $125 \mathrm{~W}$ high-pressure mercury lamp while a slow stream of argon saturated with n-heptane vapor was passed through the suspension. At regular intervals samples of the polymer were removed and dried, and their IR spectra recorded.

\section{Reaction of polystyrylmethylenecyclopentadienylchromium tricarbonyl hydride with $\mathrm{CHCl}_{3}$ and $\mathrm{NO}$}

A $0.5 \mathrm{~g}$ sample of the tricarbonyl hydride derivative was stirred in $10 \mathrm{ml}$ of dry $\mathrm{CHCl}_{3}$ for $24 \mathrm{~h}$. The IR spectrum of the product still showed absorptions at 2020 and $1920 \mathrm{~cm}^{-1}$ due to the starting material; three weak bands at 2040 , 1990 and $1950 \mathrm{~cm}^{-1}$ indicate partial formation of a tricarbonyl chloride derivative. Continued treatment with $\mathrm{CHCl}_{3}$ at reflux temperature caused complete disappearance, first of the bands at 2020 and $1900 \mathrm{~cm}^{-1}$ and then of all absorptions in the $\mathrm{CO}$ region. NO was then introduced and the mixture was stirred for $24 \mathrm{~h}$ at room temperature to give a yellow material with $\nu(N O)$ absorptions at 1800 and $1700 \mathrm{~cm}^{-1}$, indicative of the presence of a dinitrosyl chloride derivative.

\section{Polystyrylmethylenecyclopentadienylchromium dichloride}

Cyclopentadiene-substituted polymer $\left(5.3 \mathrm{~g} ; 1.8 \mathrm{mmol} \mathrm{C}_{5} \mathrm{H}_{5} / \mathrm{g}\right.$ polymer $)$ was converted into the lithium salt and treated with $4.4 \mathrm{~g} \mathrm{CrCl}_{3}$ - 3THF (11.8 $\mathrm{mmol}$ ) in tetrahydrofuran at room temperature for several days. The solid was filtered off and extracted with tetrahydrofuran in a Soxhlet apparatus overnight. The blue-green material was dried at $10^{-3}$ torr and room temperature for two days. A chromium content of $0.70 \mathrm{mmol} \mathrm{Cr} / \mathrm{g}$ and a chlorine content of $1.47 \mathrm{mmol} \mathrm{Cl} / \mathrm{g}$ indicate the presence of $\mathrm{C}_{5} \mathrm{H}_{4} \mathrm{CrCl}_{2}$ groups.

\section{Polystyrylmethylenecyclopentadienylchromium dinitrosyl chloride}

A $0.8 \mathrm{~g}$ sample of the polymer-supported cyclopentadienylchromium dichloride derivative described above was stirred overnight in $20 \mathrm{ml}$ dry tetrahydrofuran under an atmosphere of pure NO. After filtration and drying at $10^{-3}$ torr and room temperature for two days, a yellowish-green material was obtained; its IR absorptions at 1800 and $1700 \mathrm{~cm}^{-1}$ were identical with those of the product obtained from treatment of the tricarbonyl hydride derivative with $\mathrm{CHCl}_{3}$ and NO.

\section{Acknowledgements}

Financial support for this work from the Deutsche Forschungsgemeinschaft and from the Fonds der Chemischen Industrie, and a leave of absence for Dr. G. Gubitosa from the Donegani Institute, Novara, are gratefully acknowledged. We wish to thank Mrs. E. Lutz and Mrs. M. Gladys for capable technical assistance.

\section{References}

1 G. Gubitosa, M. Boldt and H.F. Brintzinger, J. Amex. Chem. Soc., 99 (1977) 5174

2 W.D. Bonds. Jr., C.H. Brabaker, Jr., E.S. Chandraseleman, C. Gibboras. R.H. Grubbs and L.C. Kroll, J. 
Amer. Chem. Soc., 97 (1975) 2128; E.S. Chandrasekaran, R.H. Grubbs and C.H. Brubaiker, Jr., Organometal. Chem., $120(1976) 49$.

3 E.O. Fischer, W. Hafner and H.O. STahl, Z. Anorg. Allg. Chem., 282 (1955) 47.

4 T.S. Piper and G. Wilkinson, J. Inorg. Nucl. Chem., 3 (1956) 104.

5 R.D. Fischer, Chem. Ber., 93 (1960) 165.

6 A. Davison. J.A. MeCleverty and G. Wilkinson, J. Chem. Soc., (1963) 1133.

7 G. Wilkinson. J. Amer. Chem. Soc., 76 (1954) 209.

8 F.A. Cotton, A.D. Liehr and G. Wilkinson, J. Inorg. Nucl. Chem., 1 (1955) 175.

9 R.D. Fischer and K. Noack. J. Organometal. Chem., 16 (1969) 125.

10 E.O. Fischer, O. Beckert, W. Hafner and M.O. Stahl, Z. Naturforsch. B. 10 (1955) 598.

11 H. Brunner, J. Organometal. Chem., 16 (1969) 119.

12 A.R. Manning and D.J. Thornhill. J. Chem. Soc. A. (1971) 637.

13 T.S. Piper and G. Wilkinson. J. Inorg. Nucl Chem., 2 (1956) 38.

14 K.W. Pepper, H.M. Paisley and M.A. Young. J. Chem. Soc., (1953) 4097.

15 R.S. Feinberg and R.B. Merrifield, Tetrahedron, 30 (1974) 3209.

16 C.U. Pittman. Jr.. P.L. Grube. O.E. Ayers, S.P. McManus, M.D. Rausch and G.A. Moser. J. Polymer Sci, A-1. 10 (1972) 379. 